\title{
Early degradation of silicon PV modules and guaranty conditions
}

\author{
M.A. Munoz ${ }^{\mathrm{a}, *}$, M.C. Alonso-García ${ }^{\mathrm{b}}$, Nieves Vela ${ }^{\mathrm{b}}$, F. Chenlo ${ }^{\mathrm{b}}$ \\ ${ }^{2}$ Dept. Rural Engineering, Electrotechnical Section, E.U.I.T. Agrícola, UPM, Avda. Complutense, s/n, 28040 Madrid, Spain \\ ${ }^{\mathrm{b}}$ Photovoltaic Laboratory, Renewable Energy, CIEMAT, Avda. Complatense, 22, 28040 Madrid, Spain
}

\begin{abstract}
The fast growth of PV installed capacity in Spain has led to an increase in the demand for analysis of installed PV modules. One of the topics that manufacturers, promoters, and owners of the plants are more interested in is the possible degradation of PV modules. This paper presents some findings of PV plant evaluations carried out during last years. This evaluation usually consists of visual inspections, $I-V$ curve field measurements (the whole plant or selected areas), thermal evaluations by IR imaging and, in some cases, measurements of the $I-V$ characteristics and thermal behaviours of selected modules in the plant, chosen by the laboratory. Electroluminescence technique is also used as a method for detecting defects in PV modules. It must be noted that new defects that arise when the module is in operation may appear in modules initially defect-free (called hidden manufacturing defects). Some of these hidden defects that only appear in normal operation are rarely detected in reliability tests (IEC61215 or IEC61646) due to the different operational conditions of the module in the standard tests and in the field (serial-parallel connection of many PV modules, power inverter influence, overvoltage on wires, etc.).
\end{abstract}

Keywords: PV module; Degradation; Defects; Module testing

\section{Introduction}

The global yearly photovoltaic installed power all over the world is continuously expanding in recent years, rising from less than $1 \mathrm{GW}$ in 2003 to more than $7.2 \mathrm{GW}$ in 2009. The increase was particularly visible in Spain, with $2.6 \mathrm{GW}$ installed in 2008 alone (EPIA, 2010). This increase was reflected in global world cumulative capacity, which approached $16 \mathrm{GW}$ at the end of 2008 . The change in Spain's tariff regulation suddenly slowed down the Spanish market and thus the world market. This, combined with the economic crisis, resulted in lower levels of global growth than the normal growth experienced at the end of 2008. Nevertheless, the development of the German market in 2009 and the continuous progression of other countries have permitted the PV market to continue to develop, with about $15 \%$ growth in 2009 . According to Lüthi (2010), the growth of the German market was due to the fact that the policy stability had a bigger influence in the photovoltaic investments than return-related factors. In this context, at the end of 2009 , the market had reached nearly $23 \mathrm{GW}$.

In order to meet the market demands, all of the actors in the PV chain accelerated module manufacturing up to the end of 2008, during which time silicon was also scarce. Growth then slowed down in 2009 (EuroObserver, 2010).

In the case of Spain, cumulative photovoltaic capacity has reached 3.5 GW (ASIF, 2010), most of the PV modules were installed between 2007 and 2009. This period coincided with a time of great dynamism in markets, high demand of PV cells and modules, and silicon shortage, which forced manufacturers to adjust their procedures in order to meet the demand. 
With this large influx of new PV systems, promoters and plants owners had to make sure that their modules fulfilled the terms expressed in the guarantee conditions and that no damage had appeared during the early stages of operation of the PV plants, as that would force the repossession of the modules. This has caused an increasing demand for testing laboratories with capabilities to analyse early degradation and hidden defects in PV modules and plants.

\subsection{Early degradation}

Apart from long-term studies that detect problems in field-aged PV modules (Reis et al., 2002; Parretta et al., 2005 ) in recent years problems have been detected in plants operating for short periods of time (Carr and Prior, 2004; Gi-Hwan Kang et al., 2010). These problems sometimes appear in PV modules as well as in other PV components. With respect to PV module defects, it is necessary to characterise and classify the types of defects and, if possible, their origins. PV module design is changing and developing, as the PV industry works to decrease costs for solar cells and panels and to improve reliability. One cost-saving strategy is to produce thinner wafers, which can cause defects if the whole process is not well adapted to reduce the risk of breakage of the cells (Pincel et al., 2009). Additionally, new thin film materials, changes in connection boxes, special designs for building integration or changes in materials are under development. Gautam and Kaushika (2002) considered 165 years as the maximum lifespan of a cell. Nevertheless, a PV system usually consists of thousands of interconnected cells and therefore the lifespan of a PV module and an array of PV modules will depend on how cells and the PV modules are interconnected.

The international mandatory standard in regards to the crystalline photovoltaic modules is IEC61215: "Crystalline silicon photovoltaic (PV) modules - design qualification and type approval" (International Electrotechnical Commission, 1987). This standard, which is described in the following point, is in place to guarantee a specific output power of PV module, together with its mechanical integrity. Nevertheless, it is very difficult to put the tests performed on the standard IEC61215 on an equal footing with the real operational conditions of PV modules. Additionally, qualification tests are performed on a small number of samples, making them insignificant with respect to annual production. Although early degradation of PV modules can be due to module design failures (these modules should not have passed the IEC61215 standard), it can also emerge when the modules are in operation. In these cases, possible reasons could be failures in manufacturing quality control, faulty PV plant design, faulty plant and/or module operation, or defects that appear after a certain time of operation that are not possible to detect with the current standards, as the standards can not cover all degradation mechanisms.

It must be mentioned that there are also some visual defects of the PV modules that appear after the module has operated for a short time that apparently do not cause a reduction in electrical module characteristics or a risk to module integrity. The evaluation of the potential risk of these types of "cosmetic" defects is important to customers and owners, as they want to be sure that their modules comply with guarantee conditions and do not have to be replaced.

Among the most common visible defects encountered, we can highlight:

- Yellowing.

- Delaminations.

- Bubbles.

- Cracks in the cells.

- Defects in the anti-reflective coating.

- Burnt cells.

\subsection{Review of IEC61215 standard}

Qualifications tests included in the IEC61215 standard have a relatively short duration and are performed on a sample of eight modules selected from the whole population of the modules production. First, these initial tests are performed on all of the modules:

- Preconditioning.

- Visual inspection.

- Maximum power determination.

- Insulation testing.

- Wet leakage testing.

After the initial testing, the modules are divided into four groups, and different electrical, mechanical and environmental tests are performed on each group. A module design passes the qualification tests, and thus is IEC approved, if each test sample meets the following criteria:

(a) Maximum output power descent does not exceed each individual test limit nor $8 \%$ after each test sequence.

(b) No open circuits during test.

(c) No visual evidence of major defects.

(d) Insulation test requirements are met after the tests.

(e) Current wet leakage test requirements are met.

(f) Specific test requirements are met.

If two or more modules do not meet these test criteria, the design does not pass the qualification requirements. If one module fails any test, then another two modules shall be subjected to the entire relevant test sequence from the beginning. If one of these modules fails, the design does not pass the qualification sequence. If both modules pass, the design has met the qualification requirements.

With respect to visual defects, the following are considered to be major visual defects:

(a) Broken, cracked or torn external surfaces.

(b) Bent or misaligned external surfaces, including superstrates, substrates, frames and junction boxes. 
(c) A crack in a cell which propagation could remove more than $10 \%$ of that cell's area from the electrical circuit of the module.

(d) Bubbles or delaminations forming a continuous path between any part of the electrical circuit and the edge of the module.

(e) Loss of mechanical integrity.

\section{Methods used for failure detection}

\subsection{Visual inspection}

Visual inspection, the first step of analysis, allows some defects to be detected by sight. Yellowing, delaminations, bubbles, cracks in cell, misalignments and burnt cells often can be detected using this method. This is usually the first step in deciding whether a PV module must be subjected to further tests. The inspection must be performed under natural sunlight to receive a good quality intense light. More than 1000 lux of illumination should be received according to test conditions for part 10.1 of the IEC61215 norm (International Electrotechnical Commission, 1987). Reflections should be avoided, as they may lead to defective images. The inspection should be done from different angles to differentiate the layer where the defect could appear and to avoid errors due to reflected images. A single photo taken from only one position is not enough because it could contain a reflected image and lead to a detection error.

\subsection{Indoor and outdoor power measurement}

The main evidence of a problem in a PV module is a decrease in the power supplied. Power decreases are not always detected within the entire population; rather, a power test must be applied individually to a set of suspicious modules. In order to detect a drop in power, a power measurement in standard test conditions (STC) must be performed. The standard test conditions consist of:

(a) Irradiance: $1000 \mathrm{~W} / \mathrm{m}^{2}$.

(b) Cell temperature: $25^{\circ} \mathrm{C}$.

(c) Spectral distribution of irradiance: AM1.5G (IEC60904-3).

(d) Normal incidence over the cell.

This test can be performed in a solar simulator (indoor measurement) or under sunlight exposure (outdoor measurement). Accurately controlling both temperature and light uniformity is not trivial (King et al., 1997). In the case of indoor measurements, temperature and light uniformity are better controlled (IEC60904-9). Nevertheless, when using artificial light, it is difficult to precisely reproduce the spectral distribution of the sunlight (IEC60891). In order to obtain an accurate measurement of the irradiance that the module tested is receiving, an appropriate choice of the reference module must be performed (Roy et al., 2010). Filters can be used to obtain the closest possible light spectral distribution to the sunlight spectrum. If the uniformity and the obtained light are very close to sunlight, the solar simulator can be classified as a class AAA simulator (IEC60904-9; Rosella and Ibáñez, 2006). The maximum error in the measurements must be taken into account, as sometimes the power decrease is not very high.

Standard Test Conditions are not the actual working conditions for PV modules. Usually, temperature will be higher than $25^{\circ} \mathrm{C}$, and the irradiation will not have the same spectrum or the same level. Rosella and Ibáñez (2006) proposed a variation of STC measurements for determining a more realistic method. Nevertheless, performing test at STC is a good way for comparing different modules under the same conditions (Kenny et al., 2006).

\subsection{Infrared images (IR)}

This test consists of the detection of areas with higher temperature than the rest (hot spots). It can occur at normal operation or in extreme conditions such as in the short circuit condition. The method used is based on the property of every material to emit electromagnetic radiation whose wavelength and relative maximum is related to the temperature of the material. This is explained by StefanBoltzman's law, which defines the equation of how an ideal or "black body" surface emits radiation. The radiation relative maximum depends on the temperature, as previously mentioned, but only three different temperature ranges are taken into account: $2-2.5 \mu \mathrm{m}$ for temperatures over $1000 \mathrm{C}$ that includes a part of visible radiation, and another two ranges; $3.5-4.2 \mu \mathrm{m}$ and $8-14 \mu \mathrm{m}$ for lower temperatures. Different ranges cannot be considered due to the high absorption of the air in the atmosphere.

Unfortunately, real materials do not emit like a black body does. Not all the energy that a body receives is emitted: rather, a part of it is absorbed or reflected. Thus, the emissivity of the surface under examination must be known in order to determine this factor and correct the equation. Krenzinger and Andrade (2007) suggested a method to perform the correction accurately by taking into account the errors due to reflections and the sky temperature. This technique is known and referred to in many previous papers (Pantelis et al., 2010; Rappich et al., 1998) that document aspects such as how images should be taken. This technique is also known as thermography (Parinya et al., 2007), as it detects the temperature of different areas and generates a graph of the surface.

Detectors based on the IR measurement method need to know the ambient temperature in order to perform corrections. Applying the Stefan-Boltzmann Law and taking into account that different materials have a different emissivity, it is possible to identify areas and points where the temperature is higher than expected as well as the exact temperature, with a reasonable error. Usually, the range of temperatures of an area under analysis is of such value that 
emissions are in the range of Infrared (IR) radiation. The system used for the detection of IR emissions of a PV module, is a video camera based on a charge coupled detector (CCD) specifically oriented towards infrared detection (IR-CCD). Nowadays Infrared Cameras have a high resolution and precision and can assist in the detection of hot spots in cells, modules or large areas of modules in a system.

\subsection{Lock in thermography (LIT)}

This is a variation of the previously mentioned IR method. This method is also non-destructive and useful in finding lateral power loss using an injection of current. In this case, a current is injected into the solar cell. The current is not continuous but rather a pulsed current, and the temperature increases wherever local shunts are situated (Breitenstein et al., 2001; Gi-Hwan kang et al., 2010). If the cell has shunt defects, they appear as local temperature modulations. It is possible to detect different kinds of shunt defects using different modulations of the currents injected.

This test can be performed in dark conditions (DLIT) or under illumination (ILIT). In the case of ILIT, cells are usually operating under open circuit condition (Voc-ILIT). Using this technique, small defects can be detected, as the detector is locked with the bias current, and it is not necessary to use such a high current. The detector is a CCD as in the case of simple IR images, and the range of wavelengths is 3-5um (the second IR window) as the temperature is in a midrange. Otwin et al. (2008) also compared this method to electroluminescence and photoluminescence methods in order to locate shunts defects.

\subsection{Electroluminescence (EL) and photoluminescence ( $P L)$ imaging techniques}

In contrast to images obtained by detecting the infrared radiation caused by the thermal effect, a luminescence image is obtained from photons emitted by the recombination of excited carriers into a solar cell (Kirchartz et al., 2009). The excitation can be achieved by means of an injected current, which provokes an electroluminescence (EL) effect. The excitation can also be obtained by means of a radiation incident over the solar cell, in which case the light obtained is due to a photoluminescence (PL) effect (Kasemann et al., 2008).

The image obtained using EL or PL technique is also an infrared image (as in the case of thermograph technique) that can be detected by an IR-CCD. In this case, the detectable defects are different from those detected using thermograph images, as the resolution of the images is better than those obtained only by the thermograph technique. EL images permit the detection of cracks in cells or areas that cannot be reached by the electricity of the excitation (Fuyuki, 2006). These areas appear dark in the images. Moreover, in cells containing cracks that do not extend all the way through the cell, this kind of test can help to detect potential future problems; dark lines appearing in the images show how a cell can suffer a complete crack if the whole photovoltaic module suffers from some extra stress.

\subsection{Resonance ultrasonic vibrations ( $R U V$ ) technique}

In order to detect cracks and micro-cracks (u-cracks) in cells, a technique based on the analysis of the ultrasonic vibrations that follow an excitation can be used (Dallas et al., 2007; Monastyrskyi et al., 2008). This technique detects deviations in the characteristic frequency of the response after an ultrasonic excitation of the wafer. A detector based on a piezoelectric transducer is situated in the periphery of the cell and a computer controlled data acquisition system is used to process the obtained data. It has been demonstrated that the resonance frequency decreases and bandwidth of the resonance frequency increases when a crack appears in a cell (Belyaev et al., 2006). This system is useful to detect cracks in standalone cells and, with some limitations, could be applied to entire PV modules.

\section{Results and discussion}

The following section presents and discusses the main detected defects:

\subsection{Yellowing and browning}

This usually consists of a degradation of the EVA or the adhesive material between the glass and the cells. It is a colour change in the material from white to yellow and sometimes then from yellow to brown. It causes a change in the transmittance of the light reaching the solar cells and thus a decrease in the power generated. Oreski and Wallner (2009) determined that the main cause of this defect in EVA and in ethylene copolymer films, is UV radiation and water exposure combined with temperatures above $50^{\circ} \mathrm{C}$ that cause a change in the chemical structure of the polymer.

Another type of yellowing has been detected during experiments. This yellowing consists of a colour change of well differentiated areas that could correspond to a change in different polymeric encapsulant used in the same module or a colour change in the material on the back side of the module from white to yellow. In the tests performed, the importance of this defect on the module's power loss cannot be assessed. Nevertheless, this yellowing could be a problem if it were to start a lack of adhesion between the polymeric encapsulant and the cells of the module, causing water penetration within the module.

In some PV modules, yellowing appears in some areas but not in adjacent areas with a different polymeric encapsulant of a different origin or characteristics. This should mean that yellowing appears in polymeric encapsulant instead of in the adherent element (usually EVA) but also that EVA was not present in the same way in both areas 
of the PV module where different polymeric encapsulant was used. Fig. 1 shows an example of how the yellowing effect appears only over an area but not in adjacent areas.

\subsection{Delamination}

Delamination consists of the loss of adherence between different layers of the PV module and the subsequent detachment of these layers. It can appear between polymeric encapsulant and cells or between cells and the front glass. Delamination is a major problem because it can lead to two effects: a light decoupling where reflection increases as well as water penetration inside the module structure. Skoczek et al. (2008) studied how this kind of defect and others such as bubbles and loss of mechanical energy could appear after some of the tests performed in IEC61215 norm. Oreski and Wallner (2005) tested different backsheet layers with damp heat test $\left(85^{\circ} \mathrm{C}\right.$ and $\left.85 \mathrm{HR}\right)$ and in some of the materials tested embrittlement was found after aging.

Delamination is more severe if it occurs in the borders of the module because, apart from the power losses, it causes electrical risks to the module and the installation. Fig. 2 presents an example of how an extreme delamination could destroy a PV module when the defect appeared after barely a year of operation in a plant. Delamination is more common in hot and humid climates. When moisture enters, different chemical reactions occur, and some cause degradation of different parts of the module. Migration of different elements through the encapsulant can react with and degrade the module. The result is often the corrosion of metals involved in the structure of the module. In such cases, the resistance could increase or an electrical failure could appear. Delamination is also related to a transmittance loss, as materials are not well optically coupled and a part of the light escapes.

\subsection{Bubbles}

This kind of defect is similar to delamination, but in this case, the lack of adherence of the EVA affects only a small area and is combined with the blowing of areas where this adherence has been lost. A bubble usually is due to a chemical reaction where some gasses are released. When it occurs in the back side of the PV module, a bulk appears

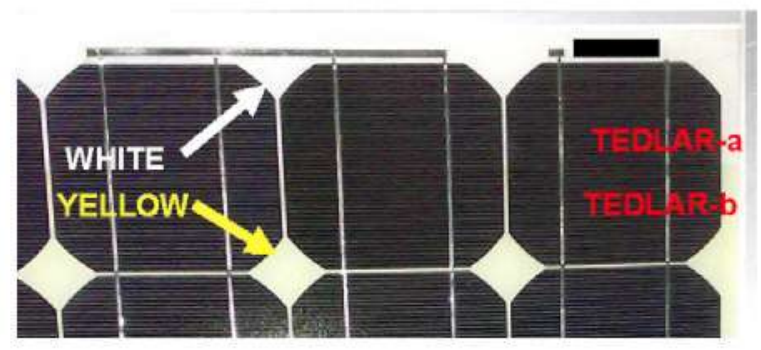

Fig. 1. Yellowing over an area of a PV module.

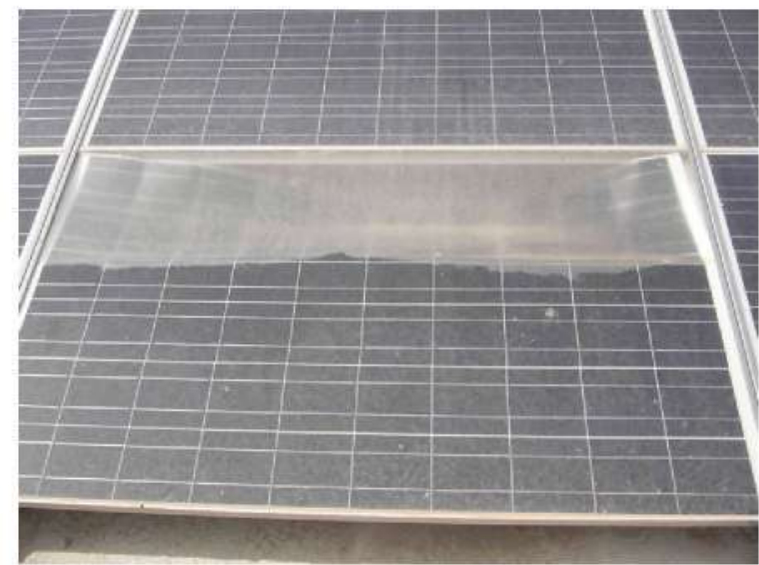

Fig. 2. PV module with severe delamination. A half of the back polymeric encapsulant fell.

in the polymeric encapsulant or the back cover, forming a bubble. Bubbles make the heat dissipation of the cells more difficult, overheating them and subsequently reducing the cell life despite the fact that the performance of the PV module could not be affected when the defect has just appeared (Mau et al., 2004). Sometimes a bubble can be only detected using IR techniques, as it is not visible though visual inspection alone but rather causes a temperature change.

A module containing a high number of bubbles in the back side in Fig. 3 can be observed. They usually appear in the centre of a cell, perhaps due to a different adherence of the cell caused by the high temperature. The bottom IR image in Fig. 3 was obtained from a PV module containing bubbles and demonstrates how a lower temperature in the back cover is detected where a bubble is situated. The bub-
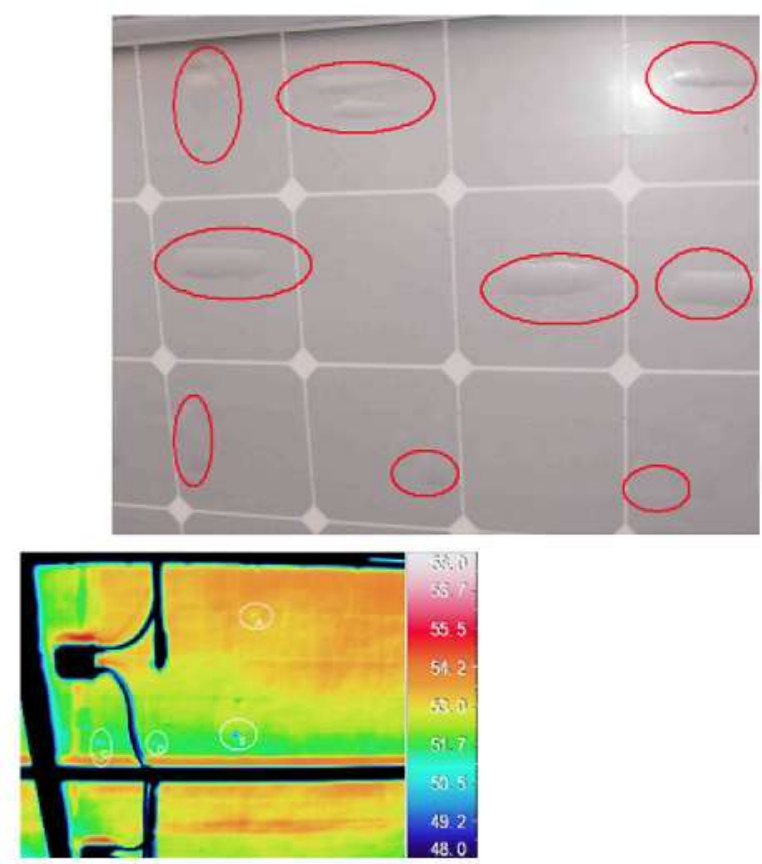

Fig. 3. Bubbles on the back side of two PV modules. 
ble forms an air chamber, and although the air temperature in the chamber appears lower than in the adjacent cells, the cell temperature is actually higher because the heat of the cell is less dissipated.

In Fig. 4, it can be observed how bubbles can also appear on the front side of a PV module between the glass and the cells. In this case, the bubbles are caused by a detachment between part of the cell and the glass. This kind of defect is not very common on the front side of the module. Bubbles usually do not appear because cells are more rigid than polymeric encapsulant. Air or gas is accumulated in the bubbles probably due to some chemical reaction as in the case of bubbles on the back side. In the case of bubbles on the front side, apart from an excess of heating effect, a reduction in the light that can reach the solar cell may occur, as there is a decoupling of the light, and the reflection is increased.

\subsection{Cracks in cells}

In order to save silicon and reduce the manufacturing cost the silicon solar cell market has varied the thickness and area of cells in the last few years. The thickness has decreased from $300 \mu \mathrm{m}$ to less than $200 \mu \mathrm{m}$, or sometimes even less than $100 \mu \mathrm{m}$. Besides the decrease of cell thickness, the area of solar cells has increased to $210 \mathrm{~mm} \times 210 \mathrm{~mm}$ (Dallas et al., 2007). This reduction of thickness and increase in area make the cells more fragile and susceptible to fractures during their manipulation, module lamination and storage.

Micro-cracks consist of small cracks in cells usually not visible by sight that may affect both sides of the cell. They produce a loss in cell consistency and a possible carrier recombination path. Sometimes different colour lines can be perceived in the cell, although the cracks are not visible by sight. When modules with these different coloured lines are tested by electroluminescence, there is good accordance between these lines and the micro-cracks observed by EL. Micro-crack areas are darker in EL because they either do not produce light emission or their emission is lower. In some cases, the cracks isolate parts of the cell avoiding current generation, as we can see in Fig. 5.

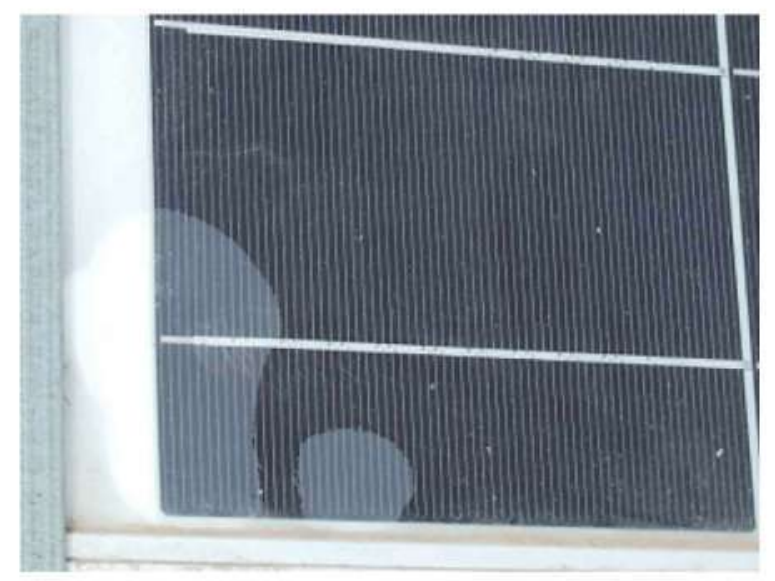

Fig. 4. Bubbles on the front side of a PV module.
Cracks and micro-cracks can also be detected using optical methods based on the detection of thin lines with different transmittances. The optical method essentially consists of applying an intense wideband light (1000 suns) and detecting the path where the light passes through the cell or, on the contrary, is blocked due to the reflections that can cause a crack. This method was used by Rueland et al. (2005) with cells and could be also adapted to be used in PV modules. Micro-cracks of less than $5 \mu \mathrm{m}$ or even of $1 \mu \mathrm{m}$ can be detected with this method.

\subsection{Defects in anti-reflective coating (ARC)}

Apart from strategies such as texturing the cell surfaces, the performance of the cells that form a PV module can be improved by adding an anti-reflective coating in order to maximize the light that reaches the active area of the cell. The materials normally used are silicon dioxide and silicon nitride, and the thickness is chosen such that only a minimal part of the light escapes. During the life of the PV module, the anti-reflective coating (ARC) receives radiation that could induce a change in the ARC colouring (Fig. 6). The anti-reflective properties may suffer changes as well, and in this case. The light that reaches the cells may be lower than expected. Nonetheless, this colour change should not cause a decrease in the wavelength radiation that the cell uses, but rather only affect a part of the visible radiation.

IR characterisation of these modules in different conditions did not show any particular effect that could be associated with the changes in the colour of the ARC. A followup of the affected modules should be done in order to detect whether this defect leads to another more severe defect. This defect is related to an oxidation of the ARC and is pointed out by Sanchez-Friera et al. (2011). The defect could be accelerated by an applied voltage of $600 \mathrm{~V}$ or higher with respect to the ground. This oxidation of the ARC could cause loss of adherence between the cells and the glass.

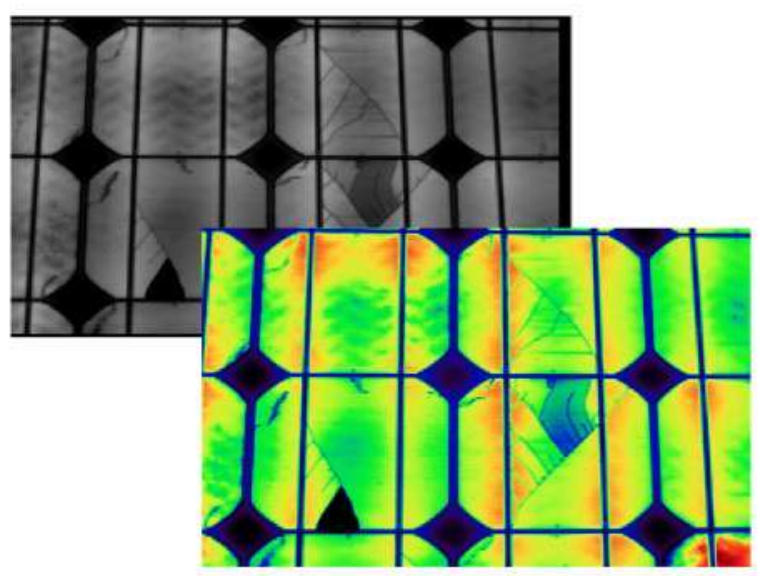

Fig. 5. Cracks in cells. B\&W image an simulated colour image. 


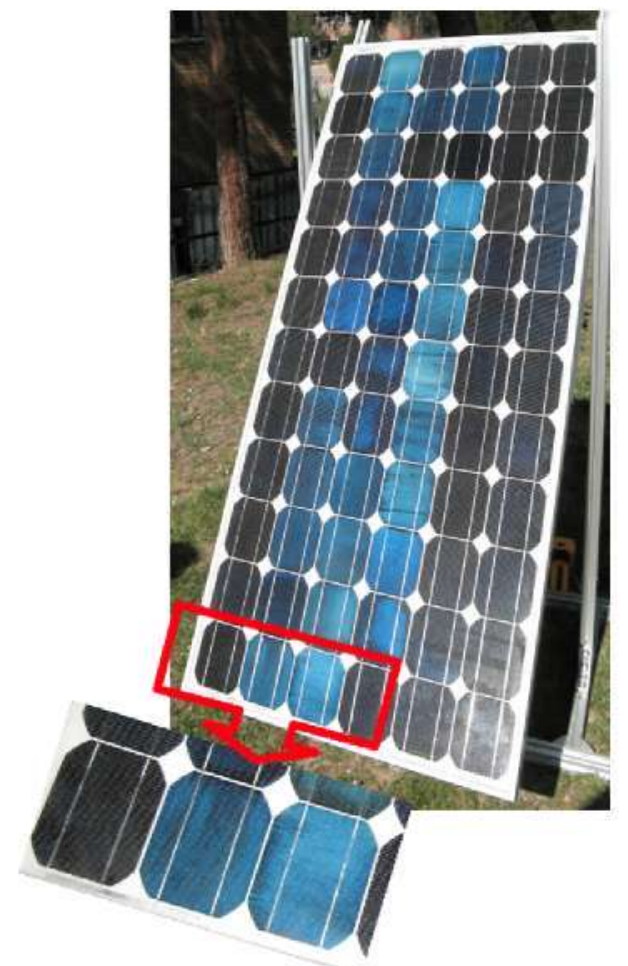

Fig. 6. Decolouring of cells due to a change in anti-reflective coating.

\subsection{Hot spots}

A hot spot is an area of a PV module that has a very high temperature that could damage a cell or any other element of the module. The cause of the hot spot could be a variety of cell failures, including partial shadowing, cells mismatch or failures in the interconnection between cells (Molenbroek et al., 1991). When a cell is shadowed, it could operate in reverse mode in which the cell consumes energy instead of generating it. Shadowing can cause hot spots if the module is not adequately protected. To prevent cell overheating and hot spots, bypass diodes are placed in connection boxes, limiting the reverse voltage that can reach a shaded cell, thereby limiting the temperature. Nevertheless, if bypass diodes distribution is not appropriated or there is a bad operation of these diodes, the shaded cell can overheat, and damage can occur in the cell or module. This can be considered a defect in the PV module (one or several of the diodes).

If the hotspot is caused by a shunt (a shortcut from one side to the other side of a cell) or an error in the interconnection between cells also generating a shortcut, the hot spot is directly related to an error in the manufacturing of the cell or of the PV module. Furthermore, if a cell generates a lower current than the rest of the cells (known as mismatch), a hot spot appears in the form of a whole cell operating at a higher temperature than the rest of the cells (Fig. 7) and can be considered an error in the manufacturing of the PV module. The hotspot could cause damage to the cell or the encapsulant within a short time of operating (Herrmann et al., 1997) (Fig. 8).

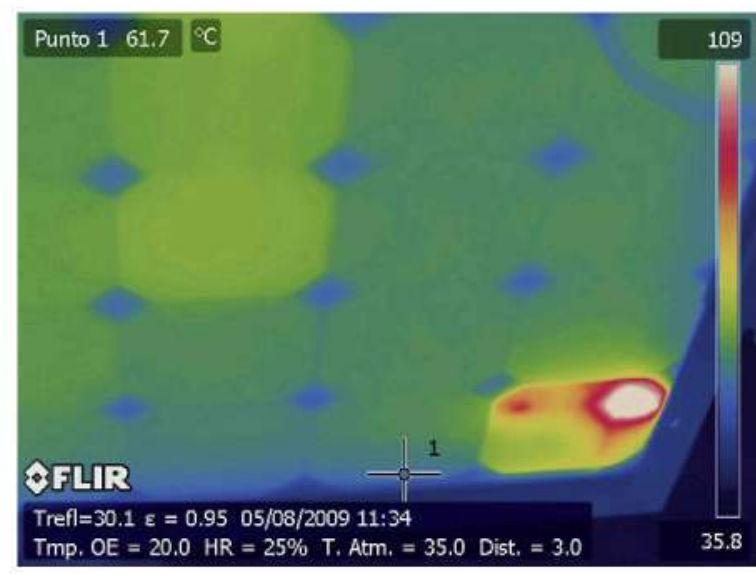

Fig. 7. Thermal analysis, where a cell operating at a higher temperature than the rest can be observed.
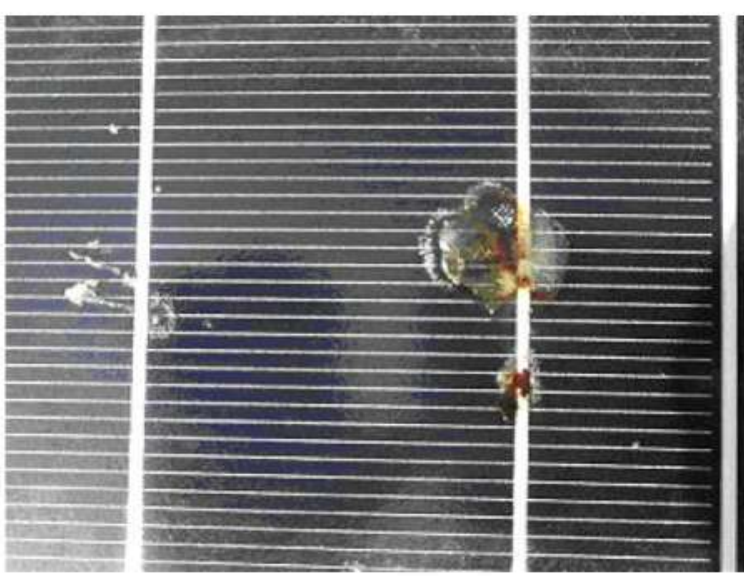

Fig. 8. This image represents how a hot spot can damage a cell.

In order to detect a hot spot defect, a thermal analysis should be performed. The analysis could be performed in normal operation, in which case the PV module could be operating in a solar plant. Another thermal test consists of the operation of the PV module at extreme conditions such as short-circuit conditions. In this case, the module should work alone, and the electrical connectors positive and negative of the module are short-circuited.

\subsection{Other defects}

\subsubsection{Lines and blemishes in the cells}

Lines that sometimes appear over a cell could be caused by a crack in the cell. It is likely that a crack led to a chemical reaction or a migration that affected the anti-reflective coating and upper layers and resulted in a visible line (Fig. 9). Using the EL method, the defect appears as a crack. Another defect consisting of a broken ribbon can also be detected. In the figure, two defects can be detected but only one of them is visible at sight as a line over a cell. In this case, the other defect can be observed using a microscope. 


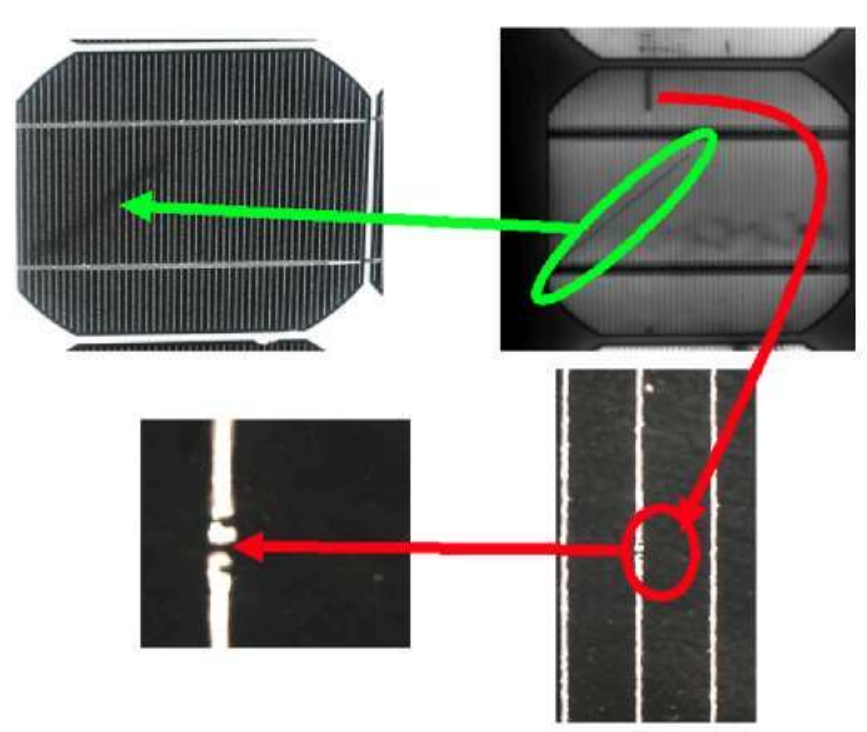

Fig. 9. Two defects detected with an EL image. The defect in the left upper image is visible by sight and consists of a crack in the cell. It can be detected using the EL method. The defect in the lower left image is only detectable using a microscope.

\subsubsection{Detachment of the frame}

The detachment of the frame consists of a separation of the frame from the rest of the module. When a detachment of the frame occurs, water can enter the module and problems such as electrical risk apart from corrosion may appear. The main cause of frame detachment is a defect in the element that acts as the adhesive and sealant, usually silicone, which should attach the frame to the set formed by glass, cells, EVA and polymeric encapsulant. Frame detachment sometimes appears after the PV module has been installed. In this case, it could be due to a faulty installation where the module supports excessive weight. An example of this can be seen in Fig. 10. Snow or ice accumulation on the module can also cause a frame detachment.

\subsubsection{Power loss exceeding the guaranteed level}

According to the norm EN 50380 (European Committee for Electrotechnical Standardization, 2003), the nominal power of the module and the allowed tolerance should appear in the label of every PV module. The mentioned nominal power should have been obtained in Standard Test Conditions (STC). Manufacturers tend to also provide a list with the measured maximum power obtained in STC of every PV module supplied known as a "flash list" (as it is usually obtained using a sun simulator based on flash light). Manufacturers also guarantee the power delivered by the module, within a range, for a certain time (usually $90 \%$ of the nominal power during $10-15$ years), increasing the time in some cases up to $20-25$ years with $80 \%$ of the nominal power. Nevertheless, in some cases, power losses higher than the ones indicated in guarantee contracts have been found when measuring modules taken out of the plants. Even this power loss appears after only a few weeks (Munoz et al., 2010). In some cases, a significant degradation (more than $4 \%$ of power loss) is reported in the first weeks of operation.

An $I-V$ curve of a defective PV module is shown in Fig. 11. It seems to have a problem on a string of cells that causes a jump in the curve. Using the EL image technique (Fig. 12) the defect in the string of cells can be confirmed, as they provide less luminescence.

Apart from an EL analysis, an $I-V$ curve analysis can be performed string by string. In this case, the $I-V$ curve of every string can be obtained by accessing the leads of the diodes in the connection box as they normally are parallel of each string. A strings analysis of the module analyzed previously was performed and Figs. 13-15 represent the $I-V$ curve of the three strings of 24 cells that form the PV module.

A power loss higher than the guaranteed loss can only be detected by periodically measuring a representative sample of the total population of the solar plant. This is a difficult test because modules under examination must be disconnected from the solar plant.

\section{Conclusions}

An initial follow-up of the modules in a plant should be done in order to detect early degradation in modules dur-

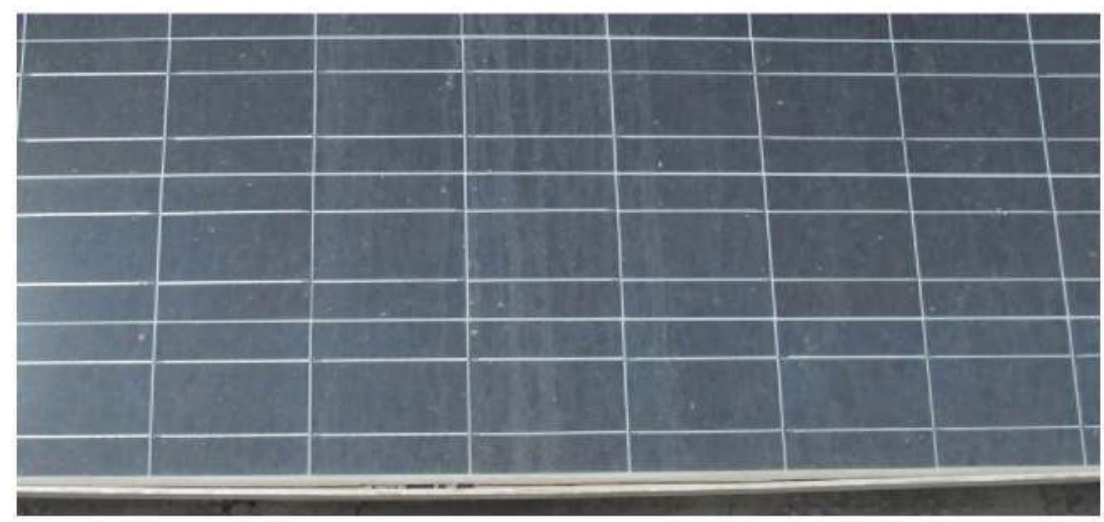

Fig. 10. Detachment of the frame. 


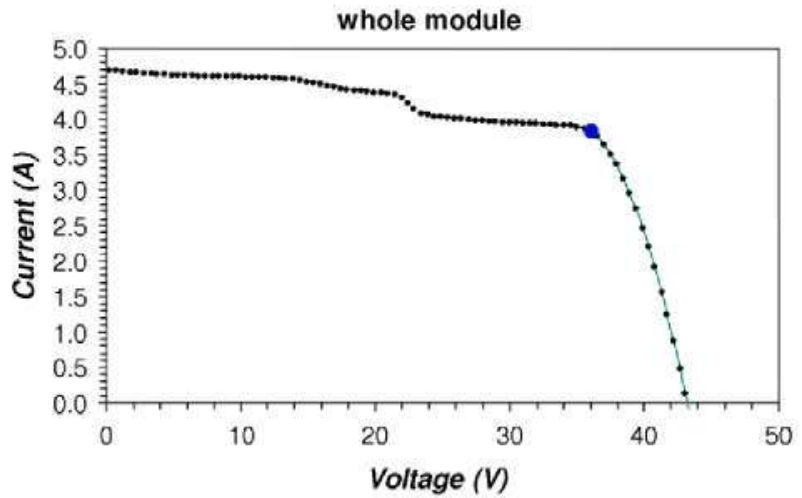

Fig. 11. Electrical $I-V$ curve of a defective module. It seems to have a problem on one string of cells.

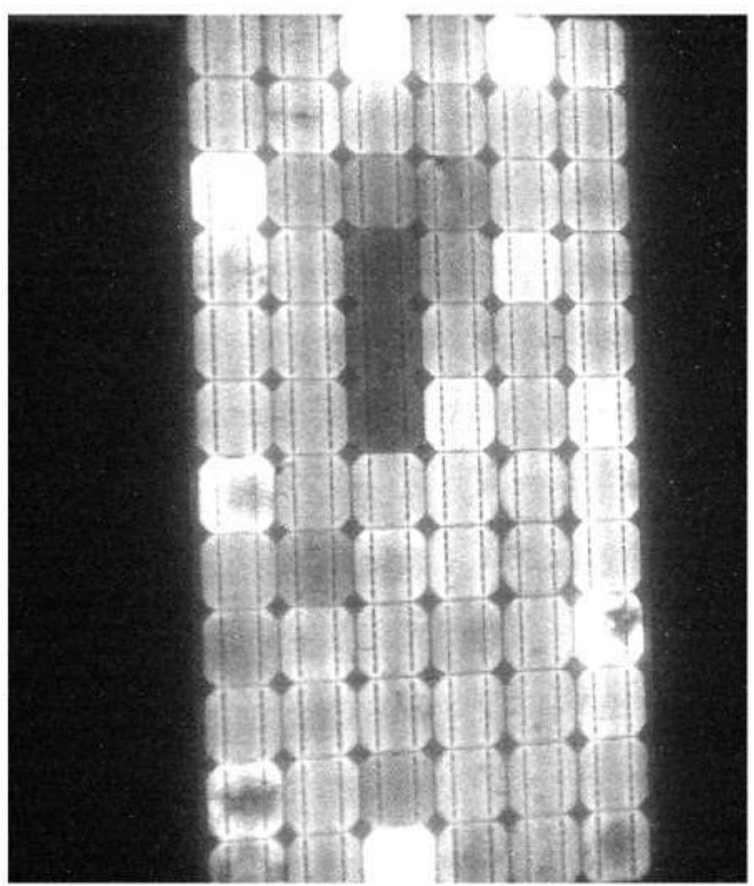

Fig. 12. EL image of the previous PV module where a defect in some cells of one string of cells is confirmed.

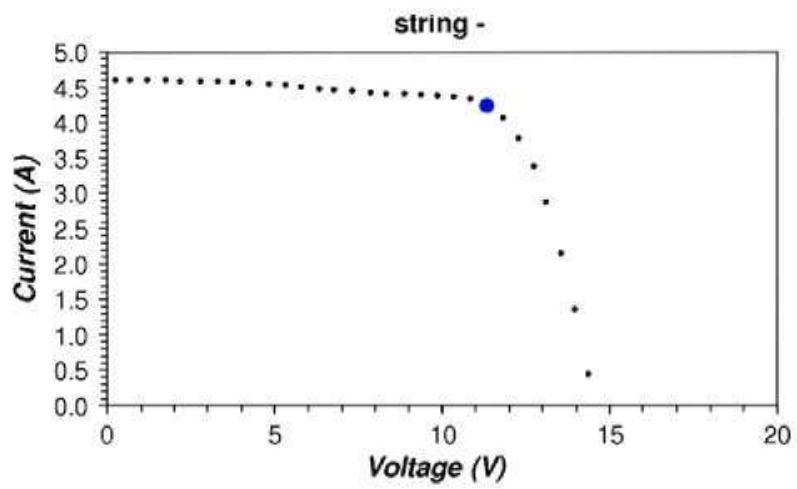

Fig. 13. $I-V$ curve of the left side string of cells of the module. It is not perfect but it is admissible.

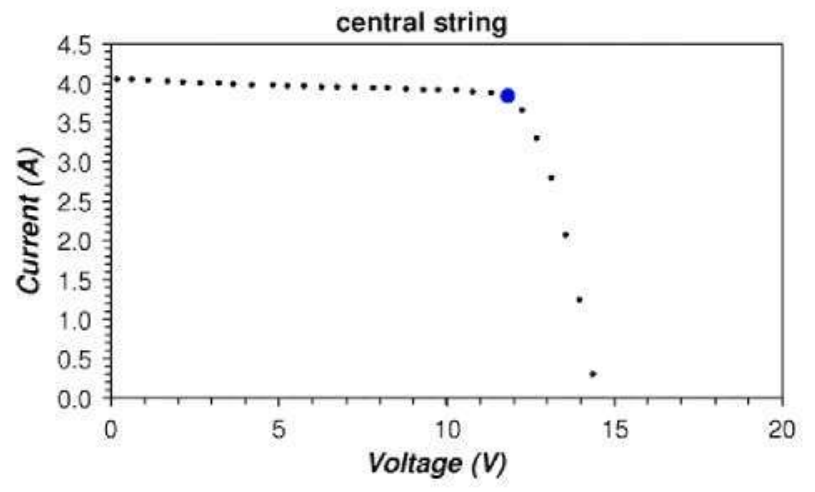

Fig. 14. I-V curve of the central string of cells of the module. The current string is clearly lower than the rest of strings.

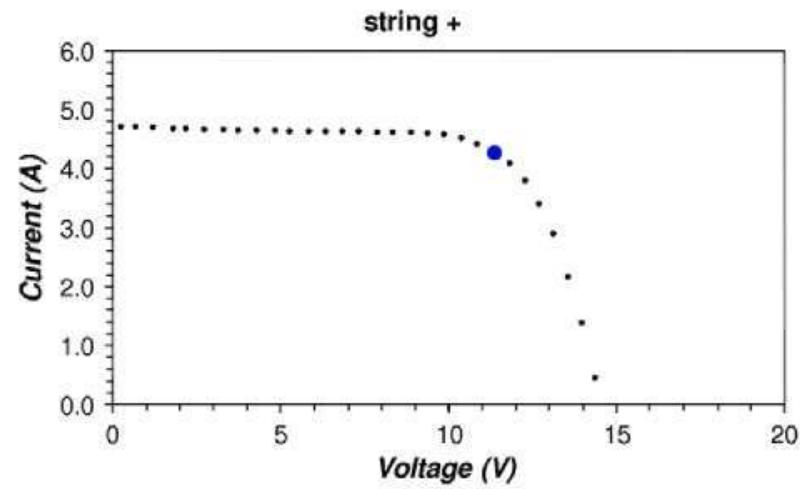

Fig. 15. $I-V$ curve of the right side string of cells of the module. It is not normal and has defects.

ing the initial guaranty period. The first step should consist of a visual inspection in order to detect defects such as bubbles, delamination, detachment of the frame, decolouring or any strange figures that may appear on the cells and that may indicate a defect. The next step should consist of a thermal analysis using an IR camera to detect any areas of the solar plant that are hotter than usual or any specific PV modules that present hot spots. A further analysis should be performed on modules containing visual defects in order to determine if the defect is real and could lead to a claim to the manufacturer of the modules. Foremost power analyses, thermal tests and EL tests should be performed.

To analyze the energy generated by a string of PV modules when there is any suspicion of a power loss, a sample of the plant's modules should be sent to a laboratory in order to determine if some of the modules have suffered a power loss higher than the allowed by the guaranty.

Cracks in he cells could appear during the manufacturing of the cells but also during the lamination process or even during the storage or installation of the module. These cracks could become a problem in the future, as they could cause a shunt or leave a part of the cell blocked. It must be determined if the problem is due to a bad design of the PV module model or it was caused by a bad operation. 


\section{Acknowledgements}

This work has been partially funded by the Spanish Ministry of Science and Innovation project EVADIFOT (reference ENE2009-14771-C02-02).

\section{References}

ASIF, Informe Anual, 2010. Hacia la Implantación Internacional de la Fotovoltaica Española (2009 data are provisional).

Belyaev, A., Polupan, O., Dallas, W., Ostapenko, S., Hess, D., Wohlgemuth, J., 2006. Crack detection and analyses using resonance ultrasonic vibrations in full-size crystalline silicon wafers. Applied Physics Letters 88, 111907-111907-3.

Breitenstein, O., Langenkamp, M., Rakotoniaina, J.P., Zettner, J., 2001 The imaging of shunts in solar cells by infrared lock-in thermography. In: Proceedings of the 17th European Photovoltaic Solar Energy Conference, Munich, Germany, 2001, pp. 1499-1502.

Carr, A.J., Prior, T.L., 2004. A comparison of the performance of different PV module types in temperate climates. Solar Energy 76, 285-294.

Dallas, W., Polupan, O., Ostapenko, S., 2007. Resonance ultrasonic vibrations for crack detection in photovoltaic silicon wafers. Measurement Science and Technology 18, 852-858.

European Photovoltaic Industry Association (EPIA), 2010. Global Market Outlook for Photovoltaics until 2014.

EuroObserver, 2010. Photovoltaic Barometer

European Committee for Electrotechnical Standardization, CENELEC Standard EN 50380: datasheet and nameplate information for photovoltaic modules. CENELEC Central Secretariat: rue de Stassart 35, B 1050 Brussels, 2003.

Fuyuki, T., 2006. Luminoscopy. A versatile tool for the diagnosis of crystalline silicon solar cells utilizing electroluminescence. In: 9th International Conference on Polycrystalline Semicoductors, POLYSE.

Gautam, Nalin K., Kaushika, N.D., 2002. Reliability evaluation of solar photovoltaic arrays. Solar Energy 72 (2), 129-141.

Gi-Hwan Kang et al., 2010. Investigation of aging phenomenon and power drop rate with field exposed PV modules. In: Proceedings of the 25th EUPVSCE, Valencia, pp. 4015-4018.

Herrmann, W., Wiesner, W., Vaassen, W., 1997. Hot spot investigations on PV modules-new concepts for a test standard and consequences for module design with respect to bypass diodes. In: Conference Record of the 26th IEEE, Anaheim, 1997, pp. 1129-1132.

International Electrotechnical Commission, 1987. Standard IEC60891. Procedures for Temperature and Irradiance Corrections to Measured $I-V$ Characteristics of Crystalline Silicon PV Devices, first ed. IEC Central Office, Geneva, Switzerland.

International Electrotechnical Commission, 1987. Standard IEC60904-1 Photovoltaic Devices. Part 1: Measurement of Photovoltaic CurrentVoltage Characteristics. IEC Central Office, Geneva, Switzerland.

International Electrotechnical Commission, 1987. Standard IEC60904-3: Photovoltaic Devices. Part 3: Measurement Principles for Terrestrial Photovoltaic (PV) Solar Devices with Reference Spectral Irradiance Data. IEC Central Office, Geneva, Switzerland.

International Electrotechnical Commission, 1987. Standard IEC60904-9: Photovoltaic Devices. Part 9: Solar Simulator Performance Requirements. IEC Central Office, Geneva, Switzerland.

International Electrotechnical Commission, 1987. Standard IEC61215 Crystalline Silicon Terrestrial Photovoltaic (PV) Modules. Design Qualification and Type Approval IEC Central Office, Geneva, Switzerland.

Kasemann, M. et al., 2008. Luminescence imaging for the detection of shunts on silicon solar cells. Progress in Photovoltaics: Research and Applications 16, 297-305.

Kenny, R.P., Dunlop, E.D., Ossenbrink, H.A., Müllejans, H., 2006. A practical method for the energy rating of c-Si photovoltaic modules based on standard tests. Progress in Photovoltaics: Research and Applications 14 (2), 155-166.
King, D.L., Kratochvil, J.A., Boyson, W.E., 1997. Temperature coeffcients for PV modules and arrays: measurement methods, difficulties, and results. In: Photovoltaic Specialists Conference, Conference Record of the Twenty-Sixth IEEE.

Kirchartz, Thomas, et al., 2009. Reciprocity between electroluminescence and quantum efficiency used for the characterization of silicon solar cells. Progress in Photovoltaics. doi:10.1002/pip.895.

Krenzinger, A., Andrade, A.C., 2007. Accurate outdoor glass thermographic thermometry applied to solar energy devices. Solar Energy 81, $1025-1034$

Lüthi, S., 2010. Effective deployment of photovoltaics in the Mediterranean countries: balancing policy risk and return. Solar Energy 84, $1059-1071$

Mau Stephan, Kramertz Thomas, Jahna Wolfgang, Fechner Hurbert, 2004. Quality testing for PV-modules according to standards and performance control for supporting manufacturing. In: Proceedings of the 19th EU PVSEC, Paris.

Molenbroek, E., Waddington, D.W., Emery, K.A., 1991. Hot spot susceptibility and testing of PV modules. In: Conference Record of the 22th IEEE, vol. 1. Las Vegas, 1991, pp. 547-552.

Monastyrskyi, A., Ostapenko, S., Polupan, O., Maeckel, H., Vazquez, M.A., 2008. Resonance ultrasonic vibrations for in-line crack detection in silicon wafers and solar cells. In: Proceedings of 33rd PVSC, 2008.

Munoz, M.A., Chenlo, F., Alonso-García, M.C., 2010. Influence of initial power stabilization over crystalline-Si photovoltaic modules maximum power. Progress in Photovoltaics: Research and Applications. doi: $10.1002 /$ pip. 1052.

Oreski, G., Wallner, G.M., 2005. Aging mechanisms of polymeric films for PV encapsulation. Solar Energy 79, 612-617.

Oreski, G., Wallner, G.M., 2009. Evaluation of the aging behavior of ethylene copolymer films for solar applications under accelerated weathering conditions. Solar Energy 83, 1040-1047.

Otwin, Breitenstein, Jan, Bauer, Thorsten, Trupke, Robert A, Bardos, 2008. On the detection of shunts in silicon solar cells by photo- and electroluminescence imaging. Progress in Photovoltaics: Research and Applications 16, 325-330.

Pantelis, N., Botsaris, John A., Tsanakas, 2010. Infrared thermography as an estimator technique of a photovoltaic module performance via operating temperarture measurements. In: The 10th European Conference on NDT, vol. 7-11. Moscow, Russia.

Parinya, P., et al., 2007. Correlation between electrical parameters of solar cells and temperature characteristics obtained from infrared thermography. Technical Digest of the International PVSEC-17, Fukuoka, Japan.

Parretta, A., Bombace, M., Graditia, G., Schioppo, R., 2005. Optical degradation of long-term, field-aged c-Si photovoltaic modules. Solar Energy Materials \& Solar Cells 86, 349-364.

Pincel, S., Zenen, Y., Frank, O., Geipel, T., Berghold, J., 2009. Mechanical stability of solar cells within solar panels. In: Proceedings of the 24th European Photovoltaic Solar Energy Conference, Hamburg, 2009, pp. 3459-3463.

Rappich, J., Mueller, M., Schneider, F., Tributsch, H., 1998. Thermographic sampling technique applied to microelectronics and photovoltaic devices. Solar Energy Materials and Solar Cells 53, 205-215.

Reis, A.M., Coleman, N.T., Marshall, M.W., Lehman, P.A., Chamberlin, C.E., 2002. Comparison of PV module performance before and after 11-years of field exposure. In: Proceedings of the 29th IEEE Photovoltaics Specialists Conference, New Orleans, Louisiana.

Rosella, J.I., Ibáñez, M., 2006. Modelling power output in photovoltaic modules for outdoor operating conditions. Energy Conversion and Management 47 (15-16), 2424-2430.

Roy, J.N., Gariki, Govardhan Raoi, Nagalakhsmi, V., 2010. Reference module selection criteria for accurate testing of photovoltaic (PV) panels. Solar Energy 84, 32-36.

Rueland, E., Herguth, A., Trummer, A., Wansleben, S., Fath, P., 2005. Optical u-crack detection in combination with stability testing for inline inspection of wafers and cells. In: Proceedings of the 20th EU PVSEC, Barcelona, 2005, pp. 3242-3245. 
Sanchez-Friera, Paula, Piliougine, Michel, Pelaez, Javier, Carretero, Jesus, de Cardona Mariano Sidrach, 2011. Analysis of degradation mechanisms of crystalline silicon PV modules after 12 years of operation in Southern Europe. Progress in Photovoltaics: Research and Applications. doi:10.1002/pip. 1083.
Skoczek, A., Sample, T., Dunlop, E.D., Ossenbrink, H.A., 2008. Electrical performance results from physical stress testing of comercial PV modules to the IEC61215 test sequence. Solar Energy Materials \& Solar Cells 92, 1593-1604. 